\title{
Livelihoods Frameworks Analysis and Selection for Chinese Rural Residents
}

\author{
SUN Zhonggen, SHI Guoqing \\ School of Public Administration, Hohai University, Nanjing, P.R. China, 210098 \\ sunzhonggen@sina.com,gshi1@126.com
}

\begin{abstract}
Livelihood is used for some development issues, especial for poverty reduction. Selecting a suitable livelihood analysis tool is quite important. There are many research frameworks of rural residents' livelihood. The representative ones are social exclusion analysis, vulnerability analysis and sustainability analysis. This paper aims to summarize the definitions of livelihood and its research tools, use SWOT to analyze different livelihood frameworks to find the characters of them. Basic on the framework analyses, this paper finds that the sustainable livelihood is a personal-oriented framework, and is more suitable for Chinese rural residents.
\end{abstract}

Index Terms - Livelihood, Framework, Rural, Comparison

\section{Definition of livelihood research framework}

According to the literatures, a large number of researchers have discussed the livelihoods. Ellis. F [1], Scoones[2], Chambers \& Conway [3] and Carney D [4] have given their definitions of rural residents' livelihoods too. Different definitions have different attitudes about the livelihood. Though the definitions are different, the elements are almost the same. Assets and the usages of these assets are both included in it. Taking the conception of CARE (Cooperative for Assistance and Relief Everywhere) for example, CARE thinks that the ability, the accessibility of tangible and intangible assets, and the related economic activities are the three basic elements of rural residents' livelihood system. The decision-making of rural residents' living is not random, but it is restrict by economic, society and assets [5].

Livelihood is used for some development issues. According to literatures, different definitions have different focuses. Selecting a suitable livelihood analysis tool is quite important. Livelihood research framework was proposed in 1990s. Basic on the definitions of livelihood, this paper thinks the livelihood research framework is a research method or a research tool which can be used to analyze the assets, find the needs of livelihood resources and give the suggestions of the usage of the livelihood assets. There are some special functions of the livelihood framework. (1) Analyzing. As a special tool, this framework can be used for analyzing and describing. (2)Diagnosis. This framework can also be used to find the lack of the assets and weakness of the livelihood strategies of rural residents. (3)Treatment. The framework can give the path by which the rural residents can get more livelihood assets, and transfer their livelihood strategies. (4) Assessment. Index system can be made to assess the livelihoods assets and strategies.

\section{Mainly livelihood research frameworks analyses}

There are many research frameworks of rural residents' livelihood. The representative ones are social exclusion analysis, vulnerability analysis and sustainability analysis.

\subsection{Social exclusion}

Social exclusion was proposed in France in 1960s, and was firstly used in social welfare policies. It was firstly used for poverty analysis by Town sen[6]. Later, some researchers proposed social exclusion framework to analyse poverty. Sen divided the social exclusion into two parts: constructive exclusion and instrumental exclusion[7]. Up to now, there are different conceptions about social exclusion, but the mainly characters are almost the same. They are these: (1) social exclusion is a process, and dynamic is one of its character.(2) there are multidimensional elements in this definition. It contains economical exclusion, political exclusion, relationship exclusion, cultural exclusion and social welfare exclusion. (3)social exclusion is both carried out by different social drivers and implementers.

\subsection{Vulnerability}

The vulnerability was firstly proposed in disaster issues. In 1980s, Robert Chambers proposed "outside- inside" research framework, and used it to analyze some development issues. Later, Prowse [8], Dercon [9] and Henninger[10] extend. Vulnerability is high related to social risks. As discussed in some papers, the definition of Dercon's is a famous one. Dercon made the risks related to poverty, and pointed that poverty can be understood by three parts: assets, incomes and welfare. These are easily crushed by social risks, and make livelihoods vulnerable. The vulnerability framework can be used in disaster assessment, environment assessment, and the vulnerability of different groups. For instance, one can assess the vulnerability of different people by their gender, age, health, income, assets and the ability of using these assets.

\subsection{Sustainable livelihoods}

Sustainable livelihoods (SL) approach was firstly brought out in 1980s, and was discussed in some poverty issues. Sen, Chambers and Conway proposed this conception and used it to discuss poverty[11]. Meanwhile, the World Commission on Environment and Development was settled up, and SL was transmitted by this group. There are some principles in this definition [12]: (1)Personal oriented. To alleviate poverty, the necessary principle of poverty alleviation is to understand the 
different needs of different groups.(2)Participation. The needy groups are the key roles of selecting and deciding a proper way of development. Some development agencies should listen to these groups' voices and make sure these groups can participle in activities. (3) Wealth enhanced and necessary ability to cope with vulnerability. (4) Comprehensive consideration. (5) Multi-level. One should propose a poverty alleviation method on different levels. (6) Corporation. It contains public agencies and private agencies. (7) Sustainable. (8)Dynamic. All of the methods to alleviate poverty should be changeable.

From some literatures, there are many different definitions about SL, and they focus on different factors. Above those frameworks, the DFID is the mostly used one[13]. SLA is a comprehensive framework to analyze the livelihood of households, and to advise people to use assets, ability and rights and take some effective measures to make the livelihood sustainable. There are five capitals in this framework, human resource capital, nature resource, financial resource, material capital and social capital. One can establish livelihood strategy by analyse social background, owned capitals and the position of social organization. Meanwhile, SLA can explain relationship between the structure of livelihood capital, processes of livelihood and livelihood target.

\section{The characters of Chinese rural residents' livelihoods}

\subsection{Dynamic}

Dynamic is a basic character of rural residents' livelihoods. With the rapid development of Chinese economic and society, most of residents' livelihoods are being in changing. For instance, more and more rural residents rush into urban areas to search jobs, especial young labours. Now days, with the development funds from governments, a great number of rural countries get more chances to develop their green and healthy planting industries. They both mean that a large number of residents have to change their livelihoods to get higher incomes to survive.

As this reason, the livelihood framework can meet this requirement, and can be used to analyze the dynamic and change ability of livelihoods. This framework should also be changeable, as the livelihoods of rural residents are changing all the time. Furthermore, this framework can focus on the changing assets and livelihoods of rural residents, for the assets and livelihoods are both in changeable. Meanwhile, frameworks should also contain some proper indexes which can be used to analyze the changing of the livelihoods, and try to find the feasible ways to make livelihoods sustainable.

\subsection{Diversity}

The livelihoods of Chinese rural residents are different. Different residents in different areas have their own livelihoods. In the south, people plant rice and bread fish for their livings, while in the north, people plant corn and wheat. Some residents also graze sheep or horses in western. Meanwhile, many residents in different areas travel frequently and resettle to make a better living, and this makes the livelihoods of Chinese more complex.

Different livelihoods lean on different assets, and different assets make the relevant livelihoods more different. The chosen framework can meet this situation, and the diversity enforces the livelihood framework be more extendable. This framework can be used to analyze different livelihoods of different groups[14].

\subsection{Distinction}

Just as discussed previously, there are many types of livelihoods in China, and these livelihoods are different. Taking the rice-planting and sheep-breading for example, the livelihood of rice-planting needs cultivated land, and it is high related to climate, while the livelihood of sheep-breading needs a great number of silages, and it is high related to sheep market. Furthermore, in some places, comparing with the sheep-breading, the rice-planting need more labours, but less capital. The chosen framework should be used to analyze the distinction of livelihoods. These differences are contained in assets and livelihood strategies. One can assess different livelihood strategies with this method, and get scientific ways to make livelihoods sustainable.

\subsection{Risky}

With necessary assets, livelihoods can get proper profits. Different livelihood strategies have different profits. Along with these profits, there are also lots of livelihood risks. For instance, some residents in south area would get less harvest because of the bad weather. Again, some rural residents in the western would also get fewer profits because of the bad market. Livelihood risks are related to the livelihood strategies. When one wants to get more profits from livelihood strategies, they may have to face more risks. These risks are caused by some visible or invisible factors which is relevant to assets.

When one chooses livelihood research frameworks, they should face these livelihood risks, and take these into consideration. The chosen framework should also have a special ability to analyze and assess these risks. From assessment, one also can get proper solutions to forecast or avoid these risks.

\section{Comparing and selection of Chinese rural residents' livelihood research frameworks}

\subsection{Comparing by SWOT}

SWOT was invented by K.J. Andrews in 1972, and it was used in strategy management ${ }^{[15]}$. One can use it to analyze the strength, weakness, opportunity and threat of a group. The strengths analysis focuses on comparison between oneself and the other groups, while the opportunity and weakness analysis focus on the affection from out-environment. The matrix is the basic framework of SWOT. This paper will use it to analyze different livelihood frameworks. The details are shown in table1. 
TABLE 1 Comparison matrix of livelihood research framework

\begin{tabular}{|c|c|c|c|}
\hline Framework & social exclusion & Vulnerability & Sustainable Livelihood \\
\hline Strength & $\begin{array}{l}\text { Focusing on special targets; } \\
\text { analyzing diversity and distinction }\end{array}$ & $\begin{array}{l}\text { clear research target; } \\
\text { focusing on assessment; } \\
\text { analyzing diversity }\end{array}$ & $\begin{array}{l}\text { Personal-oriented; } \\
\text { focusing on dynamic and diversity; } \\
\text { suitable for rural residents; } \\
\text { specialized in interaction analysis }\end{array}$ \\
\hline weakness & $\begin{array}{l}\text { unsuitable for local issues; difficult to } \\
\text { analyze the dynamics and diversities; } \\
\text { not propose some solutions }\end{array}$ & $\begin{array}{l}\text { not be system atism; } \\
\text { needing large dates; }\end{array}$ & $\begin{array}{l}\text { None quantitative analysis; } \\
\text { Needing large dates; } \\
\text { lack of risky analysis; }\end{array}$ \\
\hline opportunity & $\begin{array}{l}\text { providing a unified theory framework } \\
\text { for poverty; a special way to assess } \\
\text { poverty }\end{array}$ & $\begin{array}{l}\text { providing solutions; } \\
\text { extending research broad }\end{array}$ & $\begin{array}{l}\text { Easily for developing issues; } \\
\text { supported by current policies; } \\
\text { Good research foundation }\end{array}$ \\
\hline threat & $\begin{array}{l}\text { needing large dates; unable to analyse } \\
\text { sensitivity }\end{array}$ & unable forecast invisible risks & $\begin{array}{l}\text { Need big funds; } \\
\text { Difficult to be understood. }\end{array}$ \\
\hline
\end{tabular}

From this table, one can find that social exclusion can meet there quirements of diversity and distinction, and focuses on specific livelihoods. Nevertheless, the weaknesses of it are that: it is difficult to use it to analyze local issues, and it also has some difficulties to analyze the dynamics, diversities of livelihoods. Furthermore, it does not propose solutions for some urgent problems. The opportunity of this framework is that it provides a unified theory framework to analyse poverty, and provides a special way to assess poverty, while needing a great number of dates and losing ability to analyze the sensitivity of livelihood are the threats of this framework.

Vulnerability has a clear research target, and it focuses on livelihood assessment. Meanwhile, it also meets the requirement of diversity. Lacking of standardization and needing a great number of dates are the weaknesses of it. Fortunately, it provides solutions for livelihood problems, and the coming out of it also extends the research broad of livelihood. According to papers, the threat of this framework is that it cannot forecast the invisible risks.

Sustainable Livelihood is personal oriented, and it focuses on the dynamic and diversity of livelihood. This framework is suitable for rural residents, especial for single family, and it is specialized in analyzing the interaction between different factors. Nevertheless, this framework does not needs quantitative analysis, and some risks are also not involved in it. Fortunately, it is easily to be used in some developing areas.

\subsection{Framework selection}

Comparison analyses show that different frameworks have different characters. Firstly, in China, the livelihoods of rural residents are different. The characters of them are dynamic, diversity, distinction and risky. The selected framework should meet these requirements. Secondly, the selected framework should be easily used. In other words, an easy and good tool has been given by some researchers. Thirdly, the selected framework should be used to assess the assets and livelihoods of the special groups, and some suggestions should also be given by it after assessing. Finally, this framework can meet the requirements of the Chinese rural policies which are issued by center and local governments to accelerate the developments of the rural areas.

Basic on the analyses, Sustainable Livelihood is a personal oriented framework. It focuses on the dynamic and diversity of the livelihood and be suitable for rural residents, especial for single family. Moreover, it is specialized in analyzing the interaction between different factors, and it is easily to be used in some developing areas. Furthermore, there are large numbers of papers relevant to these which are conducted by some famous researchers. Some of the weaknesses can be overlooked with some efforts by some groups.

\section{Acknowledgment}

This research was financially supported by Philosophy and social science fund of colleges and universities in Jiangsu Province (Granted No.2012SJD630068), public welfare project of Ministry of water resources (Granted No.201301065) and the national social science fund (Granted No.13 \& ZD172).

\section{References}

[1] Ellis F. Rural Livelihoods and Diversity in Development Countries. New York: Oxford University Press, 2000.

[2] Scoones. Sustainable livelihood: A Framework for Analysis.DS Working Paper 72. Brighton: IDS, 1998.

[3] Chambers, R, and R. Conway. Sustainable Livelihoods: Practical Concepts for the 21st Century. IDS Discussion Paper, 1992.

[4] Carney D. Implementing a Sustainable Livelihood App roach. London: Department for International Development, 1998.

[5] He Wei. Progress and trend research of Chinese farmers sustainable livelihoods. Progress in Geography, 2013(4).

[6] Zeng Qun, Wei Yanbing. Losing job and social exclusion: a framework, Sociological studies, 2004.

[7] Amartya Sen. the Theory of Social Exclusion. Social Economic System, 2005(1).

[8] Mar tin Prowse, towards a clearer understanding of vulnerability in relation to chronic poverty, CPRC Working Paper, 2003(24).

[9] Stefan Dercon, Vulnerability to Poverty: A Framework for Policy Analysis, DFID working paper, 2001(1).

[10] Henninger, N. Mapping and geographic analysis of human welfare and poverty-review and assessment. World Resources Institute: Washington D. C. $1998(1)$.

[11] Naresh Singh. Let the Sustainable Livelihoods. International Social Science Journal, 2000(4). 
[12] Tang Lixia. The analyses tools of Social Exclusion, Vulnerability and Sustainable Livelihoods. Guizhou Social Sciences Magazine, 2010(12).

[13] DFID. Sustainable Livelihoods Guidance Sheets. Department for International Development, 2000.
[14] Zhao Xueyan the impacts caused by the livelihoods assets of herdsmen. Geographical Research, 2011(3).

[15] Qi Xiaojun. SWOT: a Strategy Research Method. Journal of XiDian University. 2003(3). 